Case Report

\title{
ANCIENT SCHWANNOMA OF THE CHEST WALL DIAGNOSED BY FINE NEEDLE ASPIRATION CYTOLOGY- A RARE CASE REPORT
}

\author{
Shubha P. Bhat ${ }^{1}$, Harish S. Permi ${ }^{2}$, Rohan Shetty ${ }^{3}$, Jayaram Shenoy ${ }^{4}$, Kishan Prasad ${ }^{5}$, Panna Hegde ${ }^{6}$ \\ ${ }^{1,5}$ Assistant Professor, ${ }^{2}$ Associate professor, ${ }^{6}$ Post graduate student, Department of Pathology \\ ${ }^{3}$ Assistant Professor, ${ }^{4}$ Professor, ${ }^{1}$ Department of Surgery. K. S. Hegde Medical Academy of Nitte University, \\ Deralakatte, M angalore - 575018. \\ Correspondence: \\ Harish S. Permi, \\ Associate Professor, Department of Pathology, K. S. Hegde M edical Academy, Deralakatte, M angalore - 575018. \\ Mobile : +91 99641 31827, E-mail : drharish01@gmail.com.
}

\begin{abstract}
:
Schwannomas are benign peripheral nerve sheath tumors. Ancient schwannoma is an uncommon variant of schwannoma, which is usually located in the retroperitoneum. Those located in the chest wall are extremely rare. We report a case of ancient schwannoma in a $34 \mathrm{yr}$ old male who presented with left sided chest pain, found to have a mass lesion in the chest wall radiologically. CT guided fine needle aspiration cytology showed features of ancient schwannoma which was confirmed on histopathology. Cytological findings in correlation with long standing nature and well defined borders on radiological examination of the lesion will aid in the preoperative diagnosis and proper management.
\end{abstract}

Keywords: Ancient schwannoma, chest wall, cytology

\section{Introduction:}

Schwannomas are neurogenic tumors arising from schwann cells of neural sheath. Ancient shwannoma is a variant of schwannoma which is an encapsulated tumor with benign nature. ${ }^{[1]} \mathrm{M}$ en and women are equally affected in their third and fourth decades. ${ }^{[2]}$ They are most often located in deep sites such as retroperitoneum (1). Chest wall schwannomas are rare, and presents with asymptomatic solitary mass. They produce compressive symptoms like pain, cough and dyspnea when they attain large size. ${ }^{[3]}$ Computerized tomography (CT) scan of the thorax with contrast will help in better characterization of the lesion. CT guided fine needle aspiration (FNAC) will aid in knowing the nature of the tumor. ${ }^{[4]}$ Treatment is complete surgical excision. ${ }^{[5]}$ We report a case of ancient

\begin{tabular}{|c|}
\hline Access this article online \\
\hline Quick Response Code \\
\hline
\end{tabular}
schwannoma in a 34 yr old male who came with left sided chest pain, found to have a mass lesion in the chest wall radiologically. CT guided fine needle aspiration cytology showed features of ancient schwannoma which was confirmed on histopathology.

\section{Case Report :}

A 34 yr old male presented with left sided chest pain for past 15 years. The pain was gradually progressive and was of pricking nature. There was no history of cough, palpitation or breathlessness. General and systemic examination was unremarkable. His complete hemogram, biochemical parameters were within normal limits. Chest $X$-ray revealed well defined opacity in the left mid zone with erosion of $5^{\text {th }}$ rib. CT scan of the thorax showed a well defined solid homogenous mass in $5^{\text {th }}$ intercostal space (Figure 1A). Spirometry was normal. CT guided FNAC of the lesion yielded good material. The smears showed spindly cells in clusters. The cells had elongated bland nucleus with pointed ends and indistinct cytoplasm. The cells were dispersed in myxoid matrix. Occasional verocay bodies were seen. A few cells were round to oval having mildly hyperchromatic nucleus. No necrosis or mitosis was seen (Figure 2A, B, C, D). Correlating with the long standing nature of the lesion and radiological evidence of well defined borders favoured a benign chest wall mass, and hence a diagnosis of ancient schwanoma was made. Left 


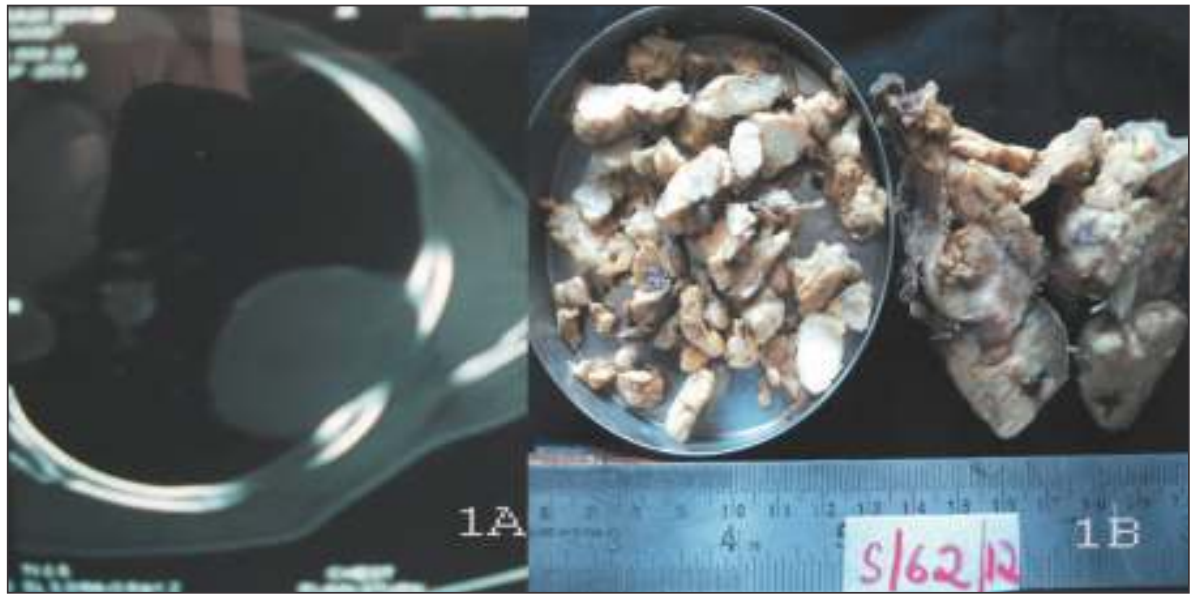

Figure 1)A- CT scan of thorax showing well defined solid homogenous mass in $5^{\text {th }}$ intercostal space. B- Gross showing partially capsulated mass. Cut surface is solid, grey white to yellowish with myxoid areas.

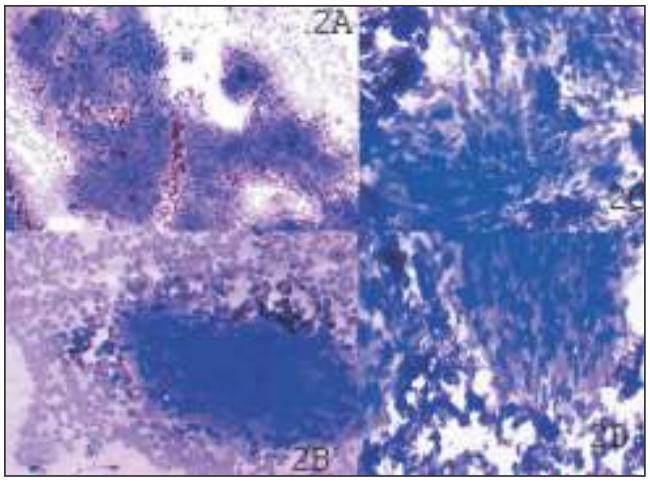

Figure 2)A, B, C, D- Microscopy smears from CT guided FNAC of the lesion showing spindly cells in clusters having elongated bland nucleus with pointed ends and indistinct cytoplasm. The cells were dispersed in myxoid matrix. Occasional verocay bodies were seen. A few cells were round to oval having mildly hyperchromatic nucleus. (M GG X400)

posterolateral thoracotomy and complete excision of the mass was done. Grossly, the mass was partially capsulated and measured $7 \times 6 \times 3 \mathrm{~cm}$. Cut surface was solid, grey white to yellowish with myxoid areas. (Figure 1B) Histopathological examination showed predominantly Antoni B areas. Occasional verocay bodies were seen. A few of the cells showed degenerative atypia and were hyperchromatic. Hyalinized blood vessels, calcification and xanthomatous change were seen (Figure 3A, B, C, D). Hence final diagnosis of ancient schwannoma was made. Postoperative period was uneventful and on follow up of two months he isfine.

\section{Discussion :}

Majority of chest wall tumors are metastatic or primary

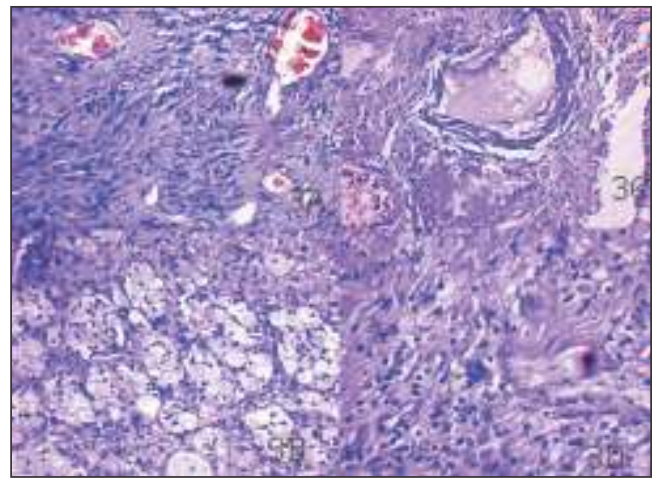

Figure 3)A, B, C, D- M icroscopy showing predominantly Antoni B areas, occasional verocay bodies, few cells showing hyperchromasia, degenerative atypia and hyalinized blood vessels, calcification and xanthomatous changes seen.(Hematoxylin \& Eosin X400)

pulmonary lesions with local invasion. Chest wall schwannoma accounts for $5 \%$ of all thoracic neoplasms. ${ }^{[4]}$ Ancient schwannoma is a distinctive type of schwannoma constitutes $0.8 \%$ of soft tissue tumors. ${ }^{[1]}$ The term "ancient" was proposed for a group of neural tumors showing degenerative changes and marked nuclear atypia. They occur as solitary tumors and may achieve a large size. Symptoms are related to pressure effect on nearby organs or sensory changes in the distribution of the affected nerve. ${ }^{[1]}$ Our patient presented to us with left sided chest pain associated with pricking sensation of the overlying skin. The initial investigation involves chest $X$-ray. ${ }^{[3]}$ Computed tomography and magnetic resonance imaging have diagnostic superiority and they can better delineate 
the tumor. ${ }^{[3]} \mathrm{CT}$ scanning is more readily available, less expensive, and can be used as first imaging modality in most cases. ${ }^{[4]}$ Fine needle aspiration of chest wall schwannomas are frequently inconclusive and has a potential that may be confused with that of a malignant tumor. ${ }^{\left[4,{ }^{6]}\right.}$ This may be due to scanty cellularity and presence of atypical cells. ${ }^{[7,8,9]}$ Cytological features of ancient schwannoma include aggregates of spindle cells with indistinct cytoplasm and elongated nucleus with pointed ends. ${ }^{[6]}$ Differential diagnosis includes neurofibroma and leiomyoma. Neurofibromas are not encapsulated and lack the biphasic pattern of schwannomas. Leiomyomas have spindle cells with tapering cytoplasm and elongated blunt ended nuclei. ${ }^{[4]}$ In our case the cells showed elongated bland nucleus with pointed ends and indistinct cytoplasm. The cells were dispersed in myxoid matrix and occasional verocay bodies were seen. Histologically, Ancient schwannoma show degenerative changes with relative loss of Antony $A$ areas and atypical nuclear features which includes hyperchromasia, multilobation but lacking mitotic figures. ${ }^{[1]}$ Other features include cystic degeneration, calcification,

References:

1. M. Kara, M.Ozkan, S. Dizbay Sak, O. Aksu, S. Kavukcu. Giant Ancient Schwannoma of the posterior mediastinum cytologically misdiagnosed as a malignant tumour. A case report. Acta Chir Belg 2002; 102: 464-6.

2. Rammos KS, Rammos SK, Foroulis CN, Zaramboukas TK. Schwannoma of the vagus nerve, a rare middle mediastinal neurogenic tumour: case report. Journal of cardiothoracic surgery 2009; 4:68

3. Ortigara L, Rosemberg N, Siqueira R, Neto F. Resection of a mediastinal schwannoma using video- assisted thoracoscopy. J Bras Pneumol. 2006; 32:172-5.

4. Sawas FA, Lababede O, M eziane M A, Arrossi AV. A 54- year old woman with incidentally discovered mass on a chest radiograph. Chest 2009, 135: 1673-8.

5. Chen F, Nakayama E, Okubo K, Date H. Intrathoracic multiple schwannomas of a single intercostals nerve. Ann Thorac Surg 2008; 86: 660-1.

6. Dodd LG, Marom EM, Dash RC, Mathews MR, McLendon RE. Fine needle aspiration cytology of ancient schwannoma. Diagn Cytopathol 1999; 20:307-11

7. Spartalis ED, Pavlopoulos D, Lachanas I, Karakatsani A, Alexandrou PI, Konstantinou K, Tomos P. A case of two simultaneous thoracic schwannomas. Pneumon 2007; 3: 258-262.

8. Petteruti F, Luca GD, Lerro A, Luciano A, Cozzolino I, Pepino P. Intercostal ancient schwannoma mimicking an apical lung tumour. Thorax 2008; 63:845-6.

9. Ozaki S, M iyata Y. Arita M , Takahashi M, Haruta R, Asahara T, Kaneko M, Kurisu K, Kataoka T. Chest wall schwannoma associated with neurofibromatosis 2- A case report. Hiroshima J M ed Sci 2004; 53:4750. xanthomatous change, interstitial hyalinization and perivascular sclerosis. ${ }^{[6]}$ Our case showed similar histological findings. Schwannomas show diffuse strong immunoreactivity to S-100. ${ }^{[4]}$ The treatment of choice of chest wall schwannoma is complete resection of the tumor. ${ }^{[5]}$ Left posterolateral thoracotomy and excision of the mass in toto was performed in our patient. Recurrence and malignant transformation of schwannomas is very rare. ${ }^{[2,5]}$ Malignant schwannomas are distinguished from benign schwannomas based on atypical mitosis, marked pleomorphism and necrosis. M ore than $50 \%$ of malignant schwannomas are found in patients with neurofibromatosis. ${ }^{[2]}$ Our patient is fine after two months of follow up.

\section{Conclusion :}

Ancient schwannomas are rare and the occurrence of it in intercostal space in the chest wall is still rarer. Cytological findings in correlation with long standing nature and well defined borders on radiological examination of the lesion will aid in the pre operative diagnosis and proper management. 